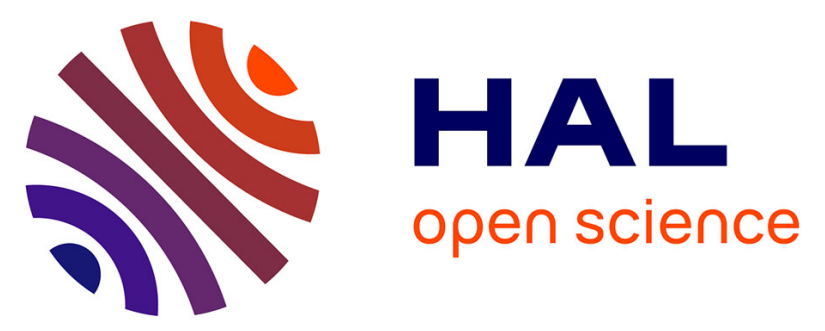

\title{
Frequency Stabilization for Multi-area Thermal-Hydro Power System Using Genetic Algorithm-optimized Fuzzy Logic Controller in Deregulated Environment
}

\author{
Yogesh Krishan Bhateshvar, Hitesh Datt Mathur, Houria Siguerdidjane, \\ Surekha Bhanot
}

\section{To cite this version:}

Yogesh Krishan Bhateshvar, Hitesh Datt Mathur, Houria Siguerdidjane, Surekha Bhanot. Frequency Stabilization for Multi-area Thermal-Hydro Power System Using Genetic Algorithm-optimized Fuzzy Logic Controller in Deregulated Environment. Electric Power Components and Systems, 2015, 43 (2), pp.146-156. 10.1080/15325008.2014.977462 . hal-01258080

\section{HAL Id: hal-01258080}

https://hal-centralesupelec.archives-ouvertes.fr/hal-01258080

Submitted on 29 Mar 2020

HAL is a multi-disciplinary open access archive for the deposit and dissemination of scientific research documents, whether they are published or not. The documents may come from teaching and research institutions in France or abroad, or from public or private research centers.
L'archive ouverte pluridisciplinaire HAL, est destinée au dépôt et à la diffusion de documents scientifiques de niveau recherche, publiés ou non, émanant des établissements d'enseignement et de recherche français ou étrangers, des laboratoires publics ou privés. 
Frequency Stabilization for Multi-Area Thermal-Hydro Power System using GA optimized Fuzzy Logic Controller in Deregulated

\section{Environment}

Y.K.Bhateshvar ${ }^{\mathrm{a}}$, H.D.Mathur ${ }^{\mathrm{a}}$, H. Siguerdidjane ${ }^{\mathrm{b}}$ and S. Bhanot ${ }^{\mathrm{a}}$

${ }^{a}$ EEE Department, BITS, Pilani Campus, Pilani, India,

${ }^{b}$ Automatic Control Department, Supélec, France

yogeshbhateshvar@gmail.com, mathurhd@gmail.com, houria.siguerdidjane@supelec.fr and surekha0057@gmail.com 


\title{
Frequency Stabilization for Multi-Area Thermal-Hydro Power System using GA Optimized Fuzzy Logic Controller in Deregulated Environment
}

\begin{abstract}
This paper develops a model of load frequency control (LFC) for an interconnected two-area thermal-hydro power system under deregulated environment. In this paper, Fuzzy Logic Controller (FLC) is optimized by genetic algorithm in two steps. First step of FLC optimization is for variables range optimization and second step is for optimization of scaling and gain parameters. Further GA optimized FLC is compared against conventional Proportional Integral Derivative (PID) controller and simple FLC. The proposed GA optimized FLC shows better dynamic response following a step load change with combination of poolco and bilateral contracts in a deregulated environment. In this paper the effect of governor dead-band (DB) is also considered. In addition, performance of GA optimized FLC also has been examined for various step load changes in different distribution units demand and compared with PID controller and simple FLC.
\end{abstract}

Keywords: Two area power system, Automatic generation control, Proportional integral derivative controller, Fuzzy logic controller, Genetic algorithm, Deregulated environment.

\section{Introduction}

In recent years, vertical integrated utility is disaggregated into independent entities Generation Companies (GENCOs), Transmission Companies (TRANSCOs) and Distribution Companies (DISCOs). In deregulated environment, GENCOs, TRANCOs and DISCOs are restructured from traditional monopoly structure to produce open competitive market. The process of deregulation was introduced for enhanced reliability and economical efficiency of power system. There is also a monitoring authority for coordination and regulation of these entities named as Independent System Operator (ISO). In order to maintain system stability, security and reliability, the ISO delivers services like Load Frequency Control [1] [2]. 


\begin{tabular}{|ll|}
\hline$f$ & \multicolumn{1}{c}{ Nomenclature } \\
$P_{L}$ & Area frequency (Hz) \\
$P_{g}$ & Real power load (p.u. MW) \\
$K_{p}$ & Turbine power output (p.u MW) \\
$T_{p}$ & Transfer function gain of generator (Hz / p.u. MW) \\
$R$ & Time constant of generator (sec.) \\
$T g$ & Regulation of the governor (Hz /p.u.MW) \\
$k_{r}$ & Time constant of the governing mechanism (sec.) \\
$T_{r}$ & Reheat coefficient of the steam turbine \\
$T_{t}$ & Reheat time constant of the steam turbine (sec.) \\
$\beta_{i}$ & Time constant of the steam turbine (sec.) \\
$a p f$ & Frequency bias constant (p.u. MW / Hz) \\
$c p f$ & Area participation factor \\
$N_{1}, N_{2}$ & Contract participation factor \\
$T_{12}$ & Fourier coefficients \\
$I A E$ & Synchronization coefficient \\
$I S E$ & Integration of absolute of error \\
\hline ITSE & Integration of square of error \\
\hline
\end{tabular}

A lot of research has been done with traditional LFC without deregulation [3-4]. In a deregulated environment, complexity of integrated power system have increased manifold making load frequency control issue a challenging one for power engineers. To ensure the quality of power supply, load frequency control based on a suitable control strategy to provide a smooth transition of generator supply with fluctuating loads is a tough challenge for power engineers. Most of earlier research has been done with linearized models of thermal and hydro units in single area and multi area power systems 
[4-5]. Literature survey also shows that not much work has been done on reheat type turbines in thermal system [10].

Keeping all these issues in concern, present system proposed in paper is modelled for two area thermal-hydro power system in deregulated environment, where reheat type turbine considered for thermal type generating units. An effect of Governor Dead Band is also considered as nonlinearity. The complete system block diagram of two area system in deregulated environment is shown in Fig. 1, in which each area contains two GENCOs and two DISCOs. When power systems are connected, tie-line flows as well as frequency must be controlled. Maintaining frequency and power interchanges with interconnected control areas at the scheduled values are the two main primary objectives of a power system LFC. The LFC for interconnected power system, achieved by measuring deviation in frequency and tie-line power flows and composite variable is called the Area Control Error (ACE) [3].

Number of different control strategies has been applied to load frequency control to minimize frequency oscillations. Researchers have been explored several optimization techniques to obtain gain parameters of PID controller for AGC. In [14], hybrid particle swarm optimization based optimized PID controller proposed for LFC. A multi-objective non-dominated shorting genetic algorithm-II technique based optimized PID controller has attempted for LFC [23]. Although, classical conventional controllers like PI and PID have been one of the favourite choices due to their simplicity and reliability, but they are not so effective for nonlinear problems arising out. Because of fluctuating load demand, operating point of a power system often changes in daily cycle. Fuzzy logic based controllers have been suggested and extensively researched as an appropriate choice to control non-linear systems [6]. FLC is very effective as its design doesn't require 
mathematical model of system and knowledge of system parameters. Already simple FLC for LFC has been explored [6-7], but for better dynamic performance optimized FLC is to be designed that can be tuned easily without a detailed knowledge of process and extensive experimentation. Few efforts reported in this direction still offer oscillatory solution [8-9].

This paper proposes LFC using GA optimized FLC for interconnected thermalhydro two area power system in a deregulated environment, having a reheat type turbine for thermal unit. A method for design of FLC and further GA optimization of the same is being done in two steps. The performance of GA optimized FLC is compared with PID controller and simple FLC for interconnected thermal-hydro two-area power system, in which control area 1 has two thermal-thermal generating units with reheat type turbine and control area 2 has two hydro-hydro generating units.

\section{System Examined}

\section{A. Two-Area Thermal-Hydro Power System in Deregulated Environment}

The system examined consists of two control areas and each having two GENCOs and two DISCOs. The Control area 1 is composed of two reheat type thermal GENCOs of equal capacity and control area 2 is composed of two hydro GENCOs of equal capacity.

The concept of contract participation factor matrix (cpf_matrix) makes easy visualization of contracts [11-12]. The number of rows indicates number of GENCOs and the number of columns indicates number of DISCOs. Here, the $\mathrm{ij}^{\text {th }}$ entry corresponds to the fraction of the total load power contracted by DISCO $\mathrm{j}$ from a GENCO i. The cpf_matrix is:

\begin{tabular}{|c|c|c|c|c|}
\hline \multirow{3}{*}{ cpf_matrix = } & Area-I & Area-I to Area-II & & \\
\hline & \multirow{2}{*}{$\begin{array}{l}c p f_{11} \\
c p f_{21}\end{array}$} & \multirow{2}{*}{$\begin{array}{l}c p f_{13} \\
c p f_{23}\end{array}$} & G1 & \\
\hline & & & $\mathrm{G}_{2}$ & \\
\hline & $c p f_{31}$ & $c p f_{33}$ & G3 & \\
\hline
\end{tabular}




\begin{tabular}{|c|c|cc|c|c|}
$c p f_{41}$ & $c p f_{42}$ & $c p f_{43}$ & $c p f_{44}$ & G4 & \\
\hline Area-II to & Area-I & Area-II & & \\
\hline D1 & D2 & D3 & D4 & \\
\hline \multicolumn{3}{|c|}{ DISCO's } \\
\end{tabular}

In $c p f \_m a t r i x$, all column entries add up to unity.

Secondary control action is based on difference between actual generation and scheduled generation, so error to represent it for interconnected power system termed as Area Control Error (ACE) [13]. ACE for interconnected power system, is:

$$
A C E_{i}=\Delta P_{t i e, i}+b_{i} \Delta f_{i}
$$

Where, $b_{i}$ is frequency bias constant, $\Delta f$ is frequency deviation and $\Delta P_{\text {tie }}$ is change in tie- line power.

Coefficients distributing ACE to several GENCOs termed as ACE participation factors (apfs) [14]. The apf_matrix is represented as:

$$
\text { apf_matrix }=\left[\begin{array}{cccc}
a p f_{1} & 0 & 0 & 0 \\
0 & a p f_{2} & 0 & 0 \\
0 & 0 & a p f_{3} & 0 \\
0 & 0 & 0 & a p f_{4}
\end{array}\right]
$$

Within a control area, sum of apfs elements adds up to unity. 


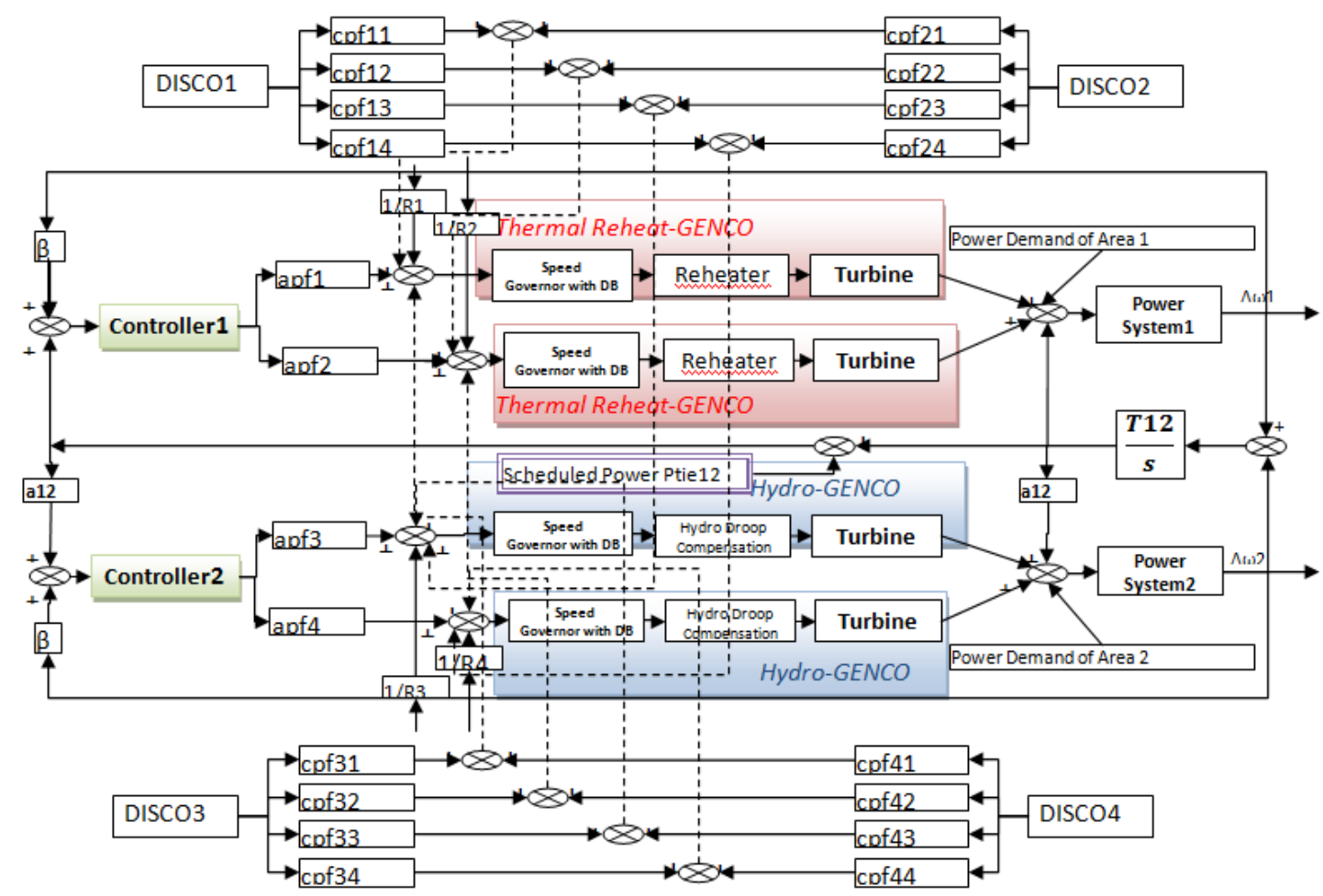

Figure 1 Complete System model of LFC of Two Area Thermal-Hydro Power System in Deregulated Environment

The contracted scheduled loads in DISCOs in Area-1 are $\Delta P_{L d 1_{1} \text { cont }} \&$ $\Delta P_{L d 2_{-} \text {Cont }}$ and in Area-2 are $\Delta P_{L d 3_{-} \text {Cont }} \& \Delta P_{L d 4_{-} C o n t}$ and these are shown in the $\Delta P_{L D \_ \text {Cont }}$ matrix.

The uncontracted local loads in area-1 $\left(\Delta P_{L d 1 \_U n c o n t} \& \Delta P_{L d 2_{-} U n c o n t}\right)$ and in area-2 $\left(\Delta P_{L d 3_{-} \text {Uncont }} \& \Delta P_{L d 4 \_ \text {Uncont }}\right)$, shown in matrix form are:

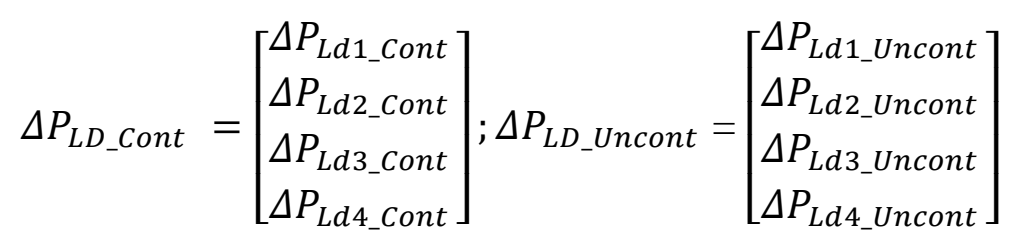

Uncontracted powers demanded under contract violation required in area$1\left(\Delta P_{L 1, L O C}\right)$ and in area-2 $\left(\Delta P_{L 2, L O C}\right)$, are demanded power by local DISCOs that demand only fulfilled by local GENCOs within same control area, as: 


$$
\Delta P_{L(i), L O C}=\sum_{j} \Delta P_{L(j) \_ \text {Uncont }}
$$

Total demanded power $\left(\Delta \mathrm{P}_{\mathrm{LD}}\right)$ that includes contracted and uncontracted power is:

$$
\Delta P_{L D}=\Delta P_{L D_{-} \text {Cont }}+\Delta P_{L D_{-} \text {Uncont }}
$$

Contracted generated powers in area-1 $\left(\Delta P_{g 1 \_ \text {Cont }} \& \Delta P_{g 2_{-} \text {Cont }}\right)$ and in area 2 $\left(\Delta P_{g 3_{3} \text { Cont }} \& \Delta P_{g 4_{-} \text {Cont }}\right)$ represented as $\Delta P_{G_{-} \text {Cont }}$ matrix. Contracted generated powers calculated from contracted demand and cpf_matrix, as shown in equation below,

$$
\Delta P_{G_{-} \text {Cont }}=c p f_{\text {matrix }} * \Delta P_{L D_{-} \text {Cont }}
$$

Uncontracted generated power from area-1 $\left(\Delta P_{g 1_{-} \text {Uncont }} \& \Delta P_{g 2_{-} \text {Uncont }}\right)$ and from area-2 $\left(\Delta P_{\text {g3_Uncont }} \& \Delta P_{g_{4}{ }_{-} \text {Uncont }}\right)$ are represented as $\Delta P_{G_{-} \text {Uncont }}$ matrix. Uncontracted generated powers calculated from uncontracted demand and apf_matrix, is:

$$
\Delta P_{G_{-} \text {Uncont }}=\text { apf_matrix } * P_{L D_{-} \text {Uncont }}
$$

Total required generation power is addition of contracted generated power and uncontracted generated power represented as:

$$
\Delta P_{G}=\Delta P_{G_{-} \text {Cont }}+\Delta P_{G_{-} \text {Uncont }}
$$

Total generated power $\left(\Delta P_{G}\right)$ through GENCOs in area-1 $\left(\Delta P_{g 1} \& \Delta P_{g 2}\right)$ and in area-2 $\left(\Delta P_{g 3} \& \Delta P_{g 4}\right)$, is:

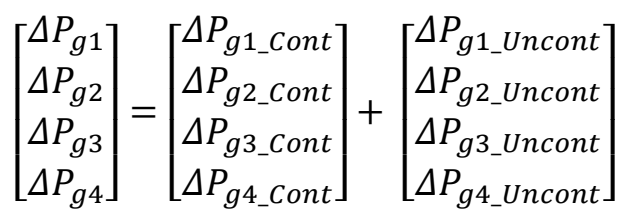

The scheduled tie line power flow between area- $i$ to area- $j$ is represented as: 


$$
\Delta P_{L, A i \rightarrow A j}=\sum_{m, n=1}^{M, N}\left(c p f_{m n} * \Delta P_{L d(n)_{-} C o n t}\right)
$$

Where $m$ is $m^{\text {th }}$ GENCO in control area $A_{i}$ and $n$ is $n^{\text {th }}$ DISCO in control area $A_{j}, M$ is total number of GENCOs in area $A_{i}$ and $N$ is total number of DISCOs in area $A_{j}$.

For two-area power system, scheduled tie line power flow between area-i and area-j is represented as:

$$
\begin{aligned}
& \Delta P_{t i e i j, s c h}=\Delta P_{L, A i \rightarrow A j}-\Delta P_{L, A j \rightarrow A i} \\
& \Delta P_{L, A 1 \rightarrow A 2}=\left(c p f_{13} * \Delta P_{L d 3_{-} \text {Cont }}+c p f_{23} * \Delta P_{L d 3_{-} \text {Cont }}+c p f_{14} * \Delta P_{\text {Ld4_Cont }}+\right. \\
& \left.c p f_{24} * \Delta P_{\text {Ld4_Cont }}\right) \\
& \Delta P_{L, A 2 \rightarrow A 1}=\left(c p f_{31} * \Delta P_{L d 1 \_C o n t}+c p f_{41} * \Delta P_{L d 1 \_C o n t}+c p f_{32} * \Delta P_{L d 2_{-} \text {Cont }}+\right. \\
& \left.c p f_{42} * \Delta P_{\text {Ld2_cont }}\right)
\end{aligned}
$$

So, scheduled tie line power flow between area-1 and area-2 is:

$$
\Delta P_{\text {tie12,sch }}=\Delta P_{L, A 1 \rightarrow A 2}-\Delta P_{L, A 2 \rightarrow A 1}
$$

\section{B. Governor Dead-Band}

Governor Dead-Band (DB) or backslash is defined as the value of a sustained speed change within which, there is no change in valve movement. The governor dead-band is important in case of small disturbance, which affects stability. Therefore, effect of governor dead-band is studied with LFC in a deregulated environment. The governor dead-band nonlinearity tends to produce a continuous sinusoidal oscillation [15].

The nonlinearity of dead-band type can be expressed as, $y=F(x, x)$

The function $F$ expressed as Fourier series is as below, 


$$
\mathrm{F}(\mathrm{x}, \dot{\mathrm{x}})=\mathrm{F}_{0}+\mathrm{N}_{1} \mathrm{x}+\frac{\mathrm{N}_{2}}{2 \pi f_{0}} \dot{\mathrm{x}}+\cdots
$$

In equation (13) if dead-band nonlinearity is assumed symmetrical about the origin and constant term $\mathrm{F}_{0}$ is equal to zero, then function $\mathrm{F}$ reduces to:

$$
\mathrm{F}(\mathrm{x}, \dot{\mathrm{x}})=\mathrm{N}_{1} \mathrm{x}+\frac{\mathrm{N}_{2}}{2 \pi f_{0}} \dot{x}
$$

With $f_{0}$ (sinusoidal oscillation frequency) of $0.5 \mathrm{~Hz}$ and backslash considered as $0.05 \%$, Fourier coefficients $\mathrm{N}_{1}$ and $\mathrm{N}_{2}$ are obtained as 0.8 and -0.2 respectively [16]. So, DB expressed in terms of transfer function is,

$$
\begin{aligned}
& \mathrm{DB}(\mathrm{s})=\mathrm{N}_{1}+\mathrm{N}_{2} \mathrm{~s} \\
& \mathrm{DB}(\mathrm{s})=\left(0.8-\frac{0.2}{\pi} \mathrm{s}\right)
\end{aligned}
$$

\section{Control Strategies}

In this paper, three different control strategies viz.: PID, simple FLC and GA optimized FLC have been simulated for selected system. This section provides discussion on controllers design and results.

\section{A. PID Controller}

In the system model in Fig.1, controller is PID controller, where, input is $A C E_{i}$ and $K_{p}$, $K_{i}$ and $K_{d}$ are gains of controller. And $u_{p i d}$ is output of controller given as:

$$
u_{p i d}=-K_{p}\left(A C E_{i}\right)-K_{i}\left(\frac{T_{S}}{1-z^{-1}}\right) A C E_{i}-K_{d}\left(\frac{1-z^{-1}}{T_{S}}\right) A C E_{i}
$$

The gains of PID controller are tuned by conventional Ziegler-Nichols (ZN) method. The ZN method is a heuristic approach to tune PID Controller. This method is based on selection of proper value of proportional gain at which sustained oscillation occurs, from 
which ultimate gain $K_{u}$ and oscillation period $T_{u}$ are obtained [17]. In present system value of ultimate gains $\left(\mathrm{K}_{\mathrm{u} 1} \& \mathrm{~K}_{\mathrm{u} 2}\right)$ and oscillation periods $\left(\mathrm{T}_{\mathrm{u} 1} \& \mathrm{~T}_{\mathrm{u} 2}\right)$ obtained, are 1 , 1.4695, 2.3 and 2.3 respectively. The gains value of PID controller calculated from $\mathrm{K}_{\mathrm{u}}$ and $\mathrm{T}_{\mathrm{u}}$, are given in Table 1.

Table 1

PID Gain based on ZN tuning method

\begin{tabular}{|l|l|l|l|}
\hline & ZN Tuned PID & Area-1PID Gains & Area-2 PID Gains \\
\hline$K_{p}$ & $0.6 \mathrm{~K}_{\mathrm{u}}$ & 0.454 & 0.66795 \\
\hline$K_{i}$ & $2 \mathrm{~K}_{\mathrm{p}} / \mathrm{T}_{\mathrm{u}}$ & 0.39525 & 0.5808 \\
\hline$K_{d}$ & $\mathrm{~K}_{\mathrm{p}} \mathrm{T}_{\mathrm{u}} / 8$ & 0.130525 & 0.192035 \\
\hline
\end{tabular}

\section{B. Fuzzy Logic Controller}

FLC is one of the popular and useful control techniques for ill-defined and nonlinear systems. It is a systematic and easier way to implement control algorithm for engineering problems. In multi-variable and complex power system, conventional control methods may not give acceptable solutions. The conventional controller works on linear models and FLC works also on nonlinear models, so FLCs are more suitable for nonlinear power system models [6-7].

The FLC consists of three steps of Fuzzification, Formation of fuzzy control rule base and Defuzzification. The control actions of an FLC are described by some set of linguistic rules, obtained from experience.

The FLC designed here is Multiple Input Single Output (MISO) type having two inputs and one output. The first input is $A C E_{i}$ and another one is change in $A C E_{i}$ (in this paper it will be further represented as $\mathrm{dACE}_{\mathrm{i}}$ ). In Fig. 2, $\mathrm{K}_{\mathrm{e}} \& \mathrm{~K}_{\mathrm{ce}}$ are scaling factors for both input variables $\left(A C E_{i}, d A C E_{i}\right)$ respectively and $\mathrm{K}_{\mathrm{p}} \& \mathrm{~K}_{\mathrm{i}}$ are the proportional and integral gains respectively. Therefore, $U_{i}$ is a crisp value obtained after defuzzification and $u_{i}$ is a final output signal from controller. 


$$
\boldsymbol{u}_{i}=-\boldsymbol{K}_{\boldsymbol{p}}\left(\boldsymbol{U}_{\boldsymbol{i}}\right)-\boldsymbol{K}_{\boldsymbol{i}}\left(\sum \boldsymbol{U}_{\boldsymbol{i}} \boldsymbol{\delta} \boldsymbol{n}\right)
$$

Table 2

Rule Base for FLC

\begin{tabular}{|l|l|l|l|l|l|l|l|l|}
\hline & \multicolumn{10}{|c|}{ dACE; } \\
\hline & \multicolumn{70}{|c|}{} \\
\hline \multirow{1}{*}{} & & VVL & VL & L & Z & H & VH & VVH \\
\cline { 2 - 10 } & VVL & VVL & VVL & VL & VL & L & L & Z \\
\cline { 2 - 10 } & VL & VVL & VL & VL & L & L & Z & H \\
\cline { 2 - 10 } & L & VL & VL & L & L & Z & H & H \\
\cline { 2 - 10 } & Z & VL & L & L & Z & H & H & VH \\
\cline { 2 - 9 } & $H$ & L & L & Z & H & H & VH & VH \\
\cline { 2 - 9 } & VH & L & Z & H & H & VH & VH & VVH \\
\cline { 2 - 10 } & VVH & Z & H & H & VH & VH & VVH & VVH \\
\hline
\end{tabular}

Fig.3 shows membership functions for input variable $A C E_{i}$ and $d A C E_{i}$, range $R_{x}$ is $R_{e}$ and $R_{c e}$ respectively and for output variable $U_{i}$, range $R_{x}$ is $R_{u}$. Initially for each variable range and membership function's distribution is same. Only trapezoidal and triangular types of membership function have been used for FLC design of system under consideration [16].

Trapezoidal type of membership function is described as [18]:

$$
f\left(x ; X_{L}, X_{C}, X_{R}\right)=\max \left(\min \left(\frac{x-X_{L}}{X_{C}-X_{L}}, \frac{X_{R}-x}{X_{R}-X_{C}}\right), 0\right)
$$

Triangular type of membership function is described:

$$
f\left(x ; X_{L}, X_{C L}, X_{C R}, X_{R}\right)=\max \left(\min \left(\frac{x-X_{L}}{X_{C L}-X_{L}}, 1, \frac{X_{R}-x}{X_{R}-X_{C R}}\right), 0\right)
$$

Table 2 presents rules for FLC utilized to design controller. Seven triangular membership functions are considered for inputs $\left(A C E_{i}\right.$ and $\left.d A C E_{i} / d t\right)$ and output $\left(u_{i}\right)$. These seven membership functions are named as Very Very Low (VVL), Very Low (VL), Low (L), Zero (Z), High (H), Very High (VH) and Very Very High (VVH). Mamdani-type fuzzy system is used for FLC modelling. The generic rule of the fuzzy inference system is written as, 
$\operatorname{RULE}(\mathbf{j} \mathbf{x} \mathbf{k})=\sum_{j=1}^{7} \sum_{k=1}^{7}$ IF $A C E_{i}=M F_{A C E_{j}}$ AND $d A C E_{i}=M F_{A C E_{k}}$ THEN $U_{i}=M F_{-} U_{j k}$

As Mamdani fuzzy theory has been applied to designing of FLC, implication method is minimum and aggregation method is maximum [19-20]. Mathematical equations for these methods shown in equation (22) and (23) are:

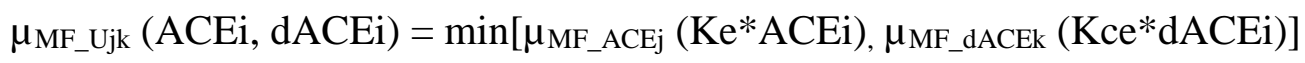

$$
\begin{aligned}
& {\left[\mu_{\mathrm{MF} \_} \mathrm{ACEj}\right.} \\
& \left.(\mathrm{Ke} * \mathrm{ACEi}) \mathrm{AND} \mu_{\mathrm{MF} \_\mathrm{dACEk}}(\mathrm{Kce} * \mathrm{dACEi})\right] \rightarrow \mu_{\mathrm{MF} \_\mathrm{Ujk}}(\mathrm{u}) \\
& \text { Aggregation }\left\{R_{1}, R_{2}, \ldots, R_{49}\right\}=\max \left\{R_{1}, R_{2}, \ldots, R_{49}\right\}
\end{aligned}
$$

Centroid method is selected as defuzzification method, mathematical expression of same is shown in following equation,

$$
\mathrm{U}=\frac{\sum_{k} \sum_{j} \beta_{\mathrm{jk}} \int \mu_{\mathrm{MF}_{-} \mathrm{Ujk}}}{\sum_{k} \sum_{j} \int \mu \mathrm{MF}_{-} \mathrm{Ujk}}
$$

Table 3 gives details of membership functions of FLC with membership function types, parameters, function and centroid values.
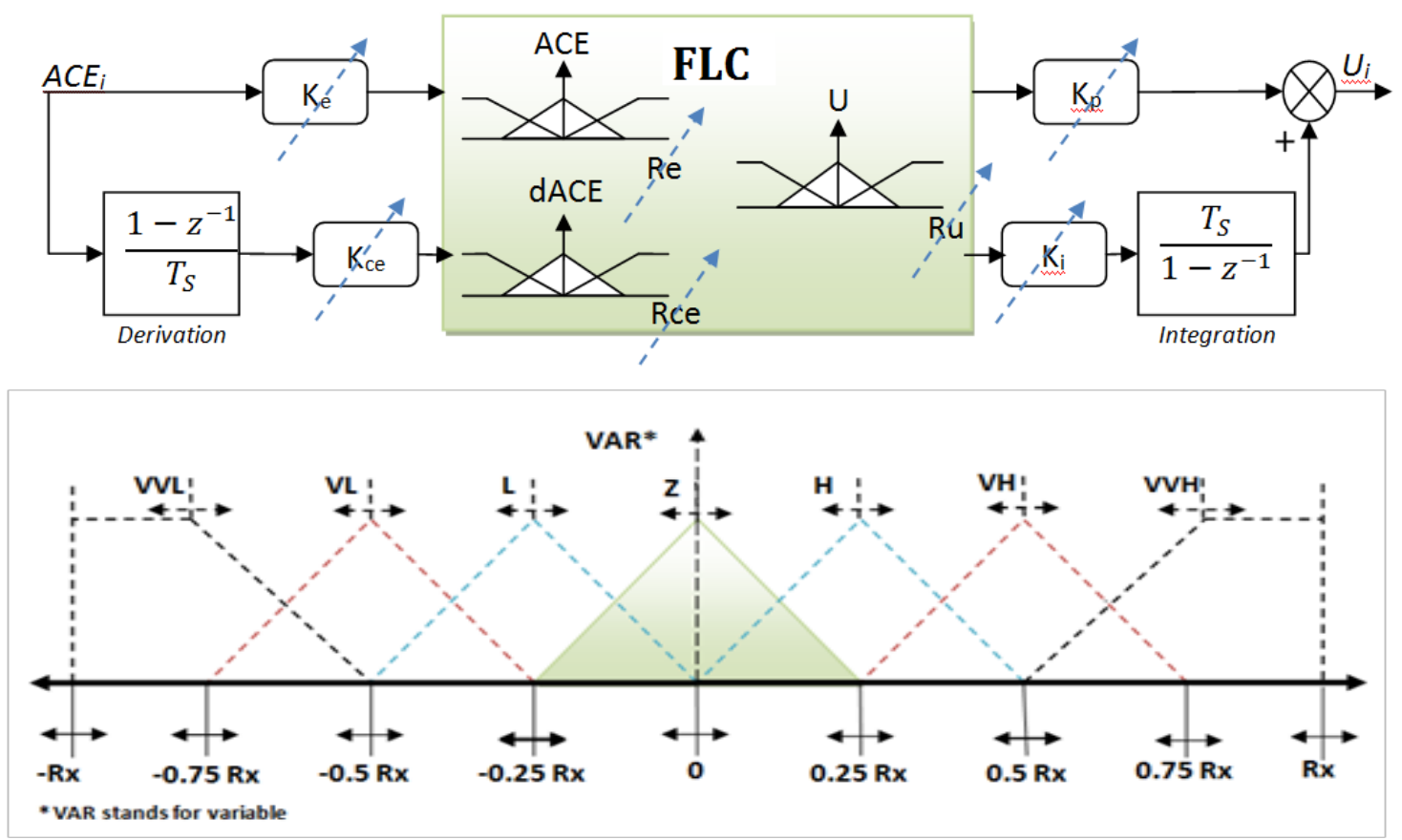
Table 3

Membership Functions details of FLC

\begin{tabular}{|c|c|c|c|c|c|c|}
\hline S.N. & MF's & MF's Type & Parameters & MF: $f(E)$ & Centroid Value $\left(\beta_{j k}\right)$ & Corresponding $\left(\beta_{j k}\right)$ \\
\hline 1 & VVL & Trapezoidal & {$\left[-1.5 R_{x}-R_{x}-0.75 R_{x}-0.5 R_{x}\right]$} & $\max (\min (0.5 \lambda E+3,1,-2-\lambda E), 0)$ & $-0.811 R_{x}$ & $\beta_{11}, \beta_{12}, \beta_{21}$ \\
\hline 2 & VL & Triangular & {$\left[-0.75 R_{x}-0.5 R_{x}-0.25 R_{x}\right]$} & $\max (\min (\lambda E+3,-\lambda E-1), 0)$ & $-0.50 R_{x}$ & $\beta_{13}, \beta_{14}, \beta_{22}, \beta_{23}, \beta_{31}, \beta_{32}, \beta_{41}$ \\
\hline 3 & $\mathrm{~L}$ & Triangular & {$\left[-0.5 R_{x}-0.25 R_{x} 0\right]$} & $\max (\min (\lambda E+2,-\lambda E), 0)$ & $-0.25 R_{x}$ & $\begin{array}{c}\beta_{15}, \beta_{16}, \beta_{24,} \beta_{25}, \beta_{33}, \beta_{34} \\
\beta_{42,}, \beta_{43}, \beta_{51,}, \beta_{52,} \beta_{61}\end{array}$ \\
\hline 4 & $\mathrm{Z}$ & Triangular & {$\left[\begin{array}{llllll}-0.25 R_{x} & 0 & 0.25 R_{x}\end{array}\right]$} & $\max (\min (\lambda E+1,1-\lambda E), 0)$ & 0 & $\beta_{17,} \beta_{26,}, \beta_{35}, \beta_{44,} \beta_{53,} \beta_{62,} \beta_{71}$ \\
\hline 5 & $\mathrm{H}$ & Triangular & {$\left[\begin{array}{llll}0 & 0.25 R_{x} & 0.5 R_{x}\end{array}\right]$} & $\max (\min (\lambda E, 2-\lambda E), 0)$ & $0.25 R_{x}$ & $\begin{array}{c}\beta_{27}, \beta_{36}, \beta_{37}, \beta_{45}, \beta_{46}, \beta_{54} \\
\beta_{55}, \beta_{63}, \beta_{64,}, \beta_{72,} \beta_{73}\end{array}$ \\
\hline 6 & $\mathrm{VH}$ & Triangular & {$\left[0.25 R_{x} 0.5 R_{x} 0.75 R_{x}\right]$} & $\max (\min (\lambda E-1,3-\lambda E), 0)$ & $0.50 \mathrm{R}_{\mathrm{x}}$ & $\beta_{47}, \beta_{56}, \beta_{57}, \beta_{65}, \beta_{66}, \beta_{74,} \beta_{75}$ \\
\hline 7 & VVH & Trapezoidal & {$\left[0.5 \mathrm{R}_{\mathrm{x}} 0.75 \mathrm{R}_{\mathrm{x}} \mathrm{R}_{\mathrm{x}} 1.5 \mathrm{R}_{\mathrm{x}}\right]$} & $\max (\min (\lambda E-2,1,3-0.5 \lambda E), 0)$ & $0.811 \mathrm{R}_{\mathrm{x}}$ & $\beta_{67}, \beta_{76}, \beta_{77}$ \\
\hline
\end{tabular}
where $\lambda=4 / \mathrm{R}_{\mathrm{x}}, \mathrm{E}=$ Variable (as Error variable), $\mathrm{R}_{\mathrm{x}}=$ Variable's MF's Range, $\mathrm{x}=\mathrm{ACE}_{\mathrm{i}}, \mathrm{dACE} \mathrm{E}_{\mathrm{i}}$ and $\mathrm{U}_{\mathrm{i}}$

\section{Genetic Algorithm(GA) based Optimization}

GA is an optimization algorithm based on natural genetics mechanics, capable of finding optimal solutions. In order to do systematic tuning of FLC, GA is a powerful optimization algorithm. In this paper, genetic algorithm optimization method is proposed for FLC optimization for decentralized control of Interconnected ThermalHydro Power System.

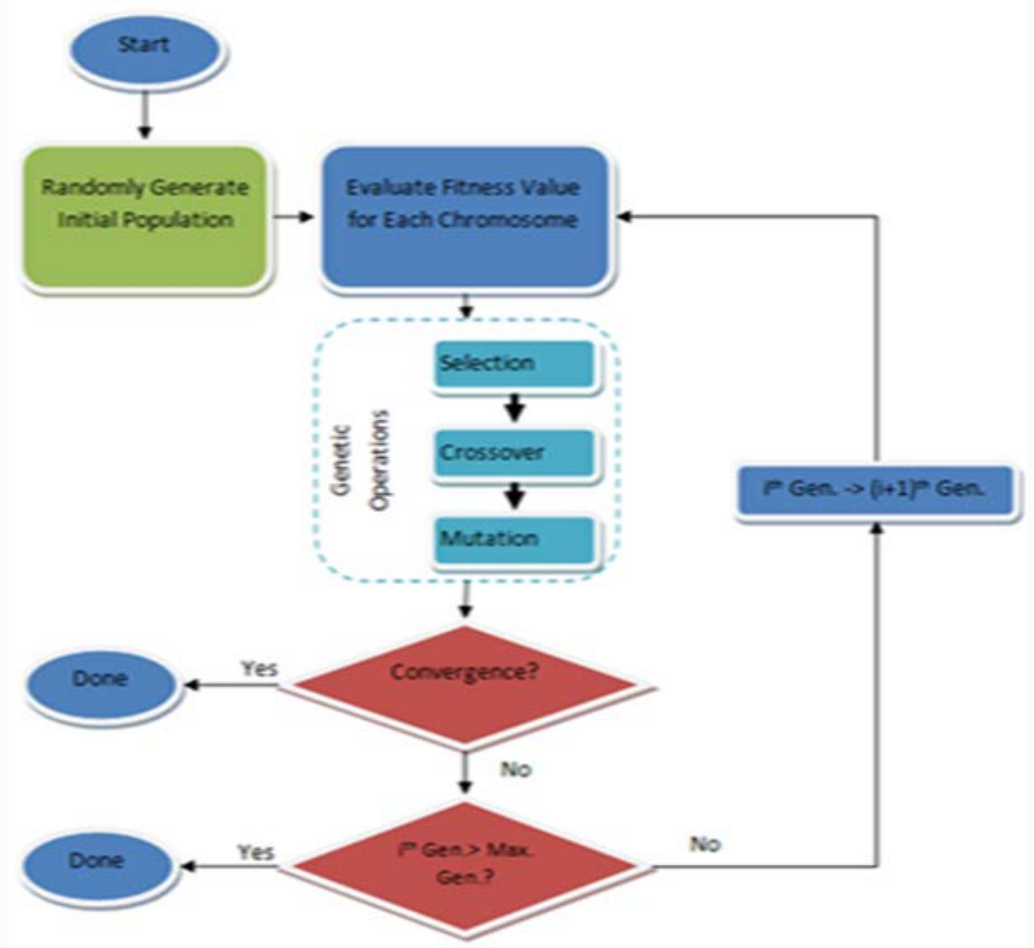

Figure 4 GA based flow Chart 
GA is an iterative procedure, size of population is fixed during every iteration, and population of new generation can be determined by following expression,

$$
P_{\text {new }}=g_{1} P_{\text {old }}+\left(1-g_{1}\right) g_{2} P_{\text {old }}+\alpha P_{\text {old }}+\beta P_{\text {old }}
$$

Where, $g_{1}$ is elitist percentage of population that is to be maintained into next population and $g_{2}$ is remainder individual percentage that is randomly selected for next population. To speed up the optimization process, Crossover rate ' $\alpha$ ' and mutation rate ' $\beta$ ' may be bigger in initial stages, and gradually become smaller in the evolution later [21].

GA optimization process is explained by flow chart shown in Fig. 4. Even GA optimization technique provides efficient and robust optimization without need to realize the mathematical model of system. Generally, it converges much faster compared to conventional optimization techniques [22].

\section{Simulated test cases}

\section{A. Simple Fuzzy Logic Controller}

In the design of simple FLC, range of input and output variables are manually selected based on experimentation and experience. This simple FLC is formed by fuzzification of input variables, the inference mechanism and defuzzification as per Mamdani fuzzy theory.

\section{B. GA Optimized Fuzzy Logic Controller}

As per Fig. 2, there are seven tunable parameters selected for optimization of FLC in two steps and steps are followed:

1) Range Optimization with constant scale of MF's: In this first step, membership functions range of input and output variables of both controllers are optimized. The 
objective function is aimed to minimize peak undershoot as well as peak overshoot of frequency and tie line deviation and minimization of settling time of frequency and tie line deviation. Optimum value of $\mathrm{R}_{\mathrm{e} 1}, \mathrm{R}_{\mathrm{ce} 1}, \mathrm{R}_{\mathrm{u} 1}, \mathrm{R}_{\mathrm{e} 2}, \mathrm{R}_{\mathrm{ce} 2} \& \mathrm{R}_{\mathrm{u} 2}$ are find out based on following objective function, as:

$$
\begin{aligned}
& J_{O B J}=\sum_{0}^{T} A *\left(\left|O V_{f 1}\right|+\left|O V_{f 2}\right|+a *\left|O V_{p t i e 12}\right|\right)+B *\left(\left|P U_{f 1}\right|+\left|P U_{f 2}\right|+b *\right. \\
& \left.\left|P U_{\text {ptie12 }}\right|\right)+C *\left(\left|S T_{f 1}\right|+\left|S T_{f 2}\right|+c *\left|S T_{\text {ptie12 }}\right|\right) \delta n
\end{aligned}
$$

Here, A, B, C, a, b and c are selected 2200, 20, 0.1, 0.1, 10 and 1 respectively and simulation time $\mathrm{T}$ is selected $50 \mathrm{sec}$ for simulation. After optimization converges, optimized parameters obtained, are:

\begin{tabular}{cccccc}
\multicolumn{3}{c}{ Area-1 } & \multicolumn{3}{c}{ Area-2 } \\
\hline $\mathrm{R}_{\mathrm{e} 1}$ & $\mathrm{R}_{\mathrm{ce} 1}$ & $\mathrm{R}_{\mathrm{u} 1}$ & $\mathrm{R}_{\mathrm{e} 2}$ & $\mathrm{R}_{\mathrm{ce} 2}$ & $\mathrm{R}_{\mathrm{u} 2}$ \\
\hline 0.0349 & 0.907 & 1.1265 & 0.345 & 2.394 & 0.2597 \\
\hline
\end{tabular}

2) Scaling Factor \& Gain Optimization: In this second step, optimum value of scaling factors $\left(\mathrm{K}_{\mathrm{e} 1}, \mathrm{~K}_{\mathrm{ce} 1}, \mathrm{~K}_{\mathrm{e} 2}\right.$ \& $\left.\mathrm{K}_{\mathrm{ce} 2}\right)$ and gain parameters $\left(\mathrm{K}_{\mathrm{p} 1}, \mathrm{~K}_{\mathrm{i} 1}, \mathrm{~K}_{\mathrm{p} 2}\right.$ \& $\left.\mathrm{K}_{\mathrm{i} 2}\right)$ for each of controller are find out. In step 2, initial value of these search parameters is kept at one. Objective function selected for this step is also same as step 1.

Optimized parameters obtained, are:

\begin{tabular}{cccccccc}
\multicolumn{4}{c}{ Area-1 } & \multicolumn{5}{c}{ Area-2 } \\
\hline $\mathrm{K}_{\mathrm{e} 1}$ & $\mathrm{~K}_{\mathrm{ce} 1}$ & $\mathrm{~K}_{\mathrm{p} 1}$ & $\mathrm{~K}_{\mathrm{i} 1}$ & $\mathrm{~K}_{\mathrm{e} 2}$ & $\mathrm{~K}_{\mathrm{ce} 2}$ & $\mathrm{~K}_{\mathrm{p} 2}$ & $\mathrm{~K}_{\mathrm{i} 2}$ \\
\hline 0.1003 & 0.8179 & 0.35195 & 0.16232 & 1.41875 & 1.49219 & 0.1122 & 0.99147 \\
\hline
\end{tabular}

In this FLC optimization process, all seven MF's for each variables are equally distributed in a ratio mentioned in Fig. 3. Both of these steps involves genetic algorithm to find optimum values of search parameters.

\section{Test Case A: Sudden Load Change}

Combinations of poolco and bilateral based transactions have been considered for both test cases A and B. In this case all the DISCOs contract power with the GENCOs for power as per the DISCO participation matrix (cpf_matirx). Each DISCO demands in pu 
MW power from GENCOs is defined by cpf's in cpf_matrix and each GENCO participation in LFC is defined by apfs, and in this case all apfs equal to 0.5. And cpf_matrix is:

$$
\begin{gathered}
\text { cpf_matrix }=\left[\begin{array}{llll}
0.25 & 0.35 & 0.20 & 0.30 \\
0.30 & 0.25 & 0.15 & 0.25 \\
0.25 & 0.25 & 0.30 & 0.25 \\
0.20 & 0.15 & 0.35 & 0.20
\end{array}\right] \\
\Delta P_{L D_{\text {Cont }}}=\left[\begin{array}{l}
0.005 \\
0.010 \\
0.010 \\
0.020
\end{array}\right] ; \Delta P_{L D_{\text {Uncont }}}=\left[\begin{array}{l}
0.00 \\
0.00 \\
0.00 \\
0.00
\end{array}\right] ;
\end{gathered}
$$

In this case demanded power is within contract limit to meet demand. Generated powers scheduled from different GENCOs are:

$$
\Delta P_{G}=\left[\begin{array}{l}
0.01275 \\
0.01050 \\
0.01175 \\
0.01000
\end{array}\right]
$$

So, for this case, tie-line power flow is, calculated from equation (9), (10) and (11), as:

$$
\begin{gathered}
\Delta P_{L, A 1 \rightarrow A 2}=0.0145 \& \Delta P_{L, A 2 \rightarrow A 1}=0.0063 \\
\Delta P_{\text {tie12,sch }}=0.082
\end{gathered}
$$

\section{Test Case B: Variable Load Demand from DISCOs}

In this test case, the system performance is evaluated for variable step load demand at different time from different DISCOs. For this test case, performance indices are measured at different time for controller's performance evaluation. Two error functions IAE and ITAE are also considered as performance indices, and these are calculated from equations below respectively. 


$$
J_{I A E}=\sum_{0}^{T}\left(\left|\triangle A C E_{1}\right|+\left|\Delta A C E_{2}\right|\right) \delta n
$$

$$
J_{I T A E}=\sum_{0}^{T} n\left(\left|\triangle A C E_{1}\right|+\left|\triangle A C E_{2}\right|\right) \delta n
$$

\section{Simulated Results}

\section{A. Sudden Load Change}

GA optimized FLC has been applied to a two area thermal-hydro power system using Matlab/Simulink as a simulation tool. Frequency deviations of both areas and tie line deviation after a sudden load change in each area for test cases are shown in Fig. 5. To evaluate the performance of proposed controller, peak undershoot, peak overshoot and settling time are selected as performance indices. Proposed controller shows better results with comparison to simple FLC and PID controller, as shown in Fig. 6 and 7.

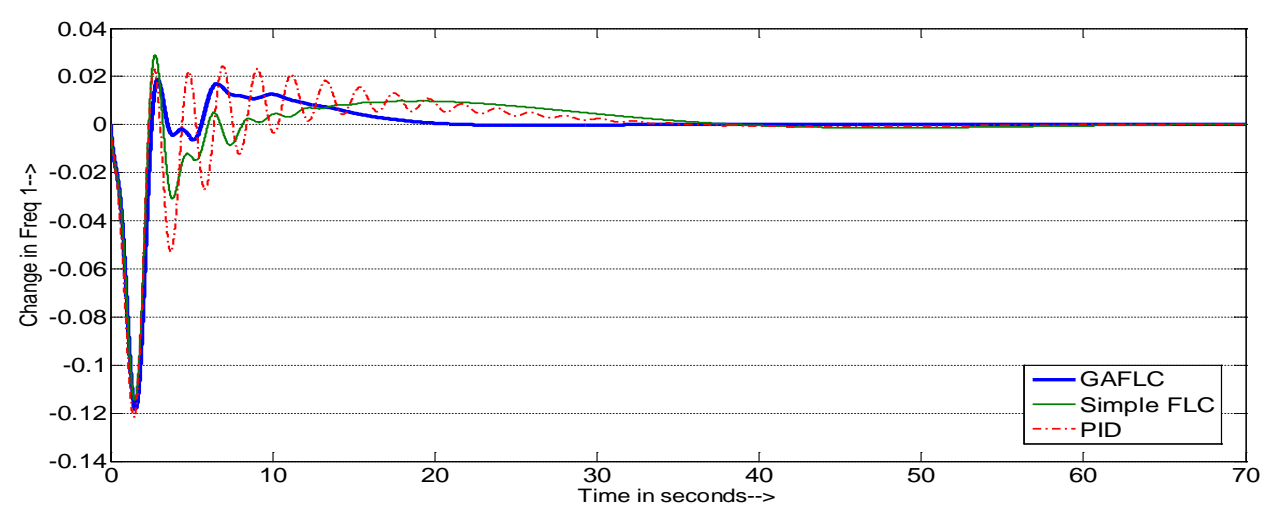

(a) 


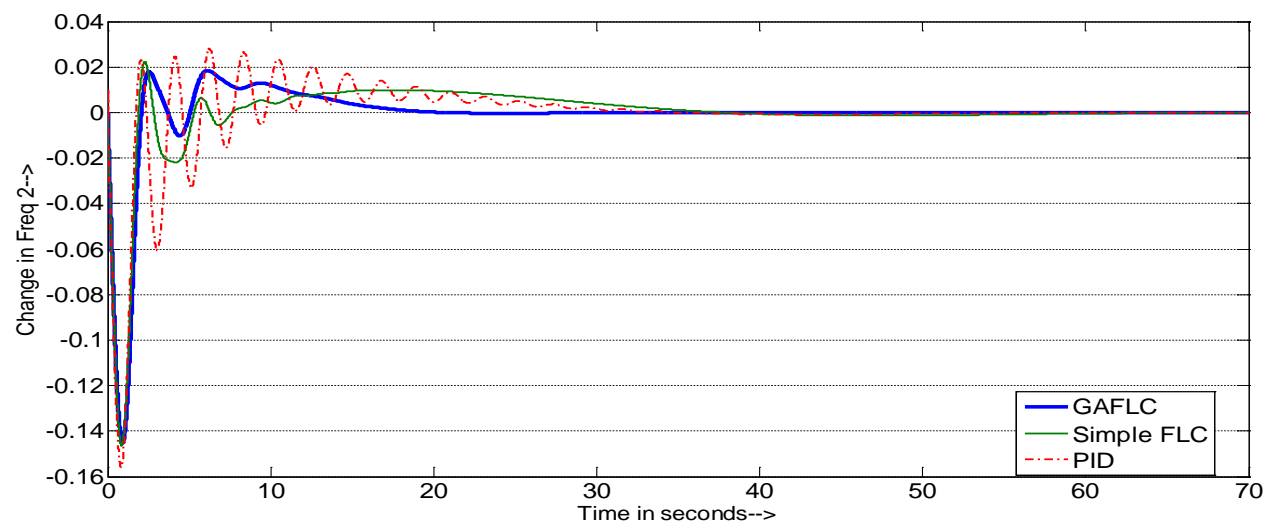

(b)

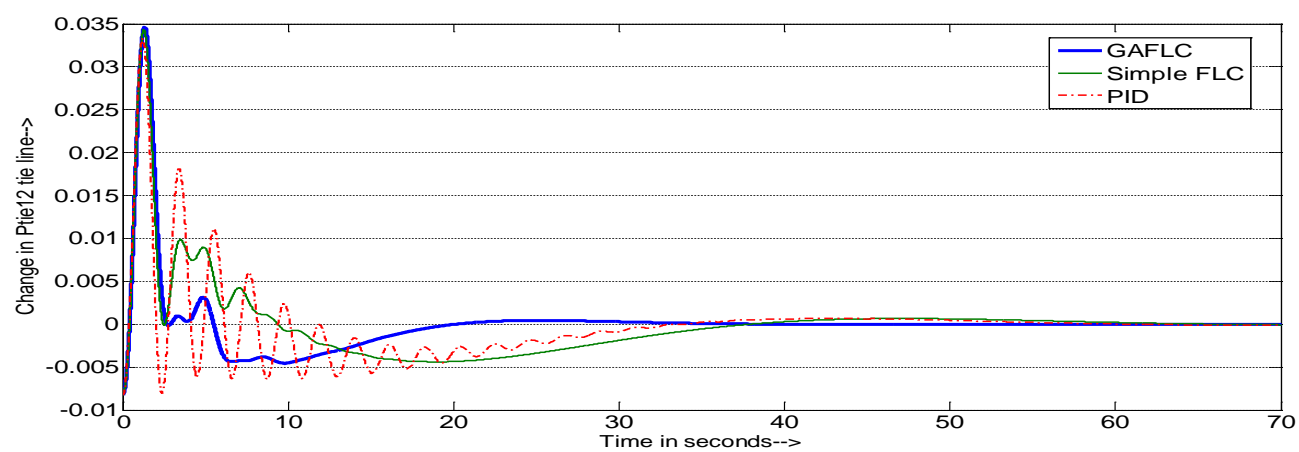

(c)

Figure 5 Comparison of two-step optimized FLC, simple FLC and PID for two area thermal-hydro power system with step load change (a) $\Delta f_{1}$, (b) $\Delta f_{2}$, (c) $\Delta$ Ptie $12_{2}$

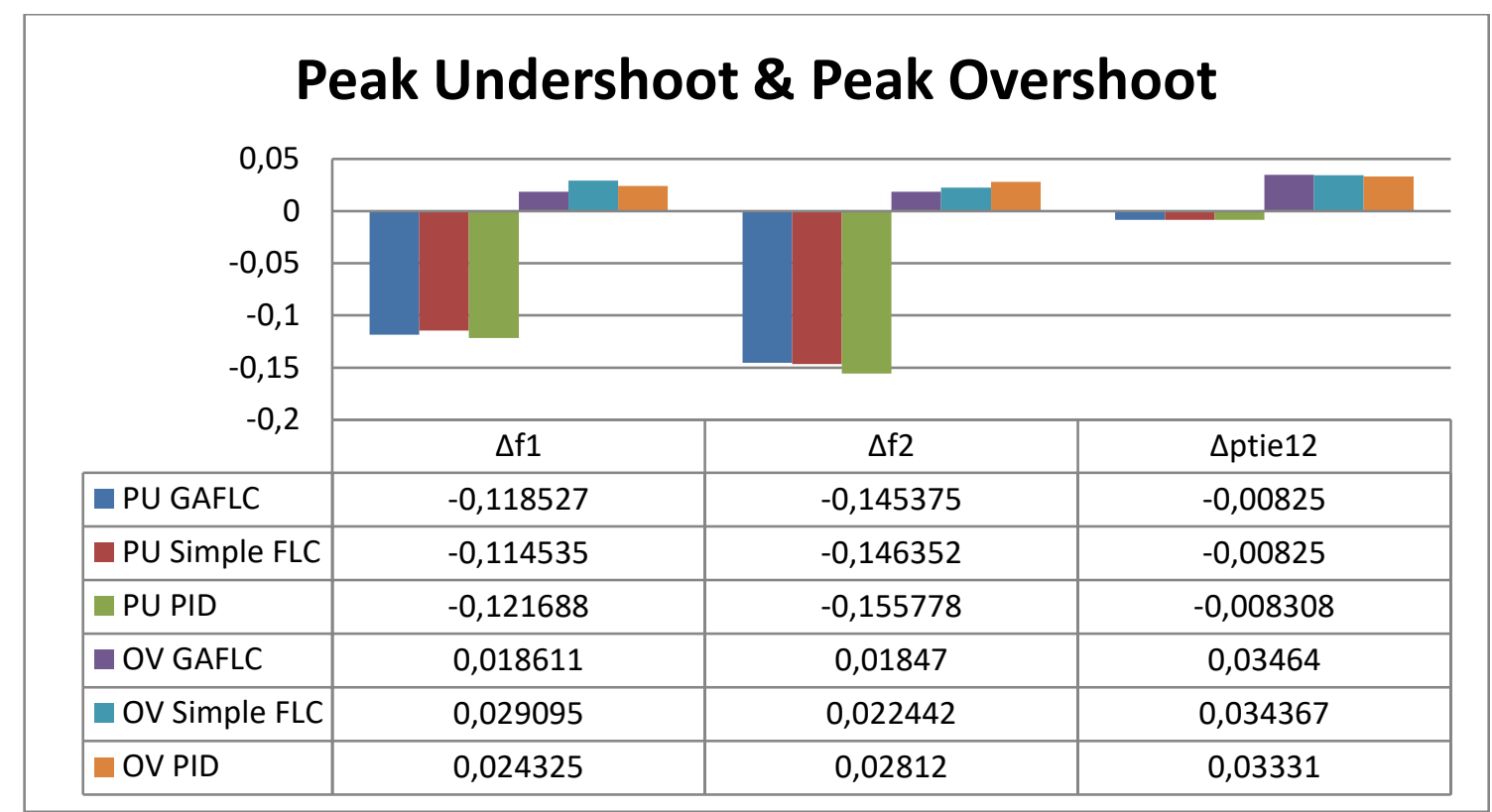

Figure 6 Peak undershoot and peak overshoot comparison of controllers 


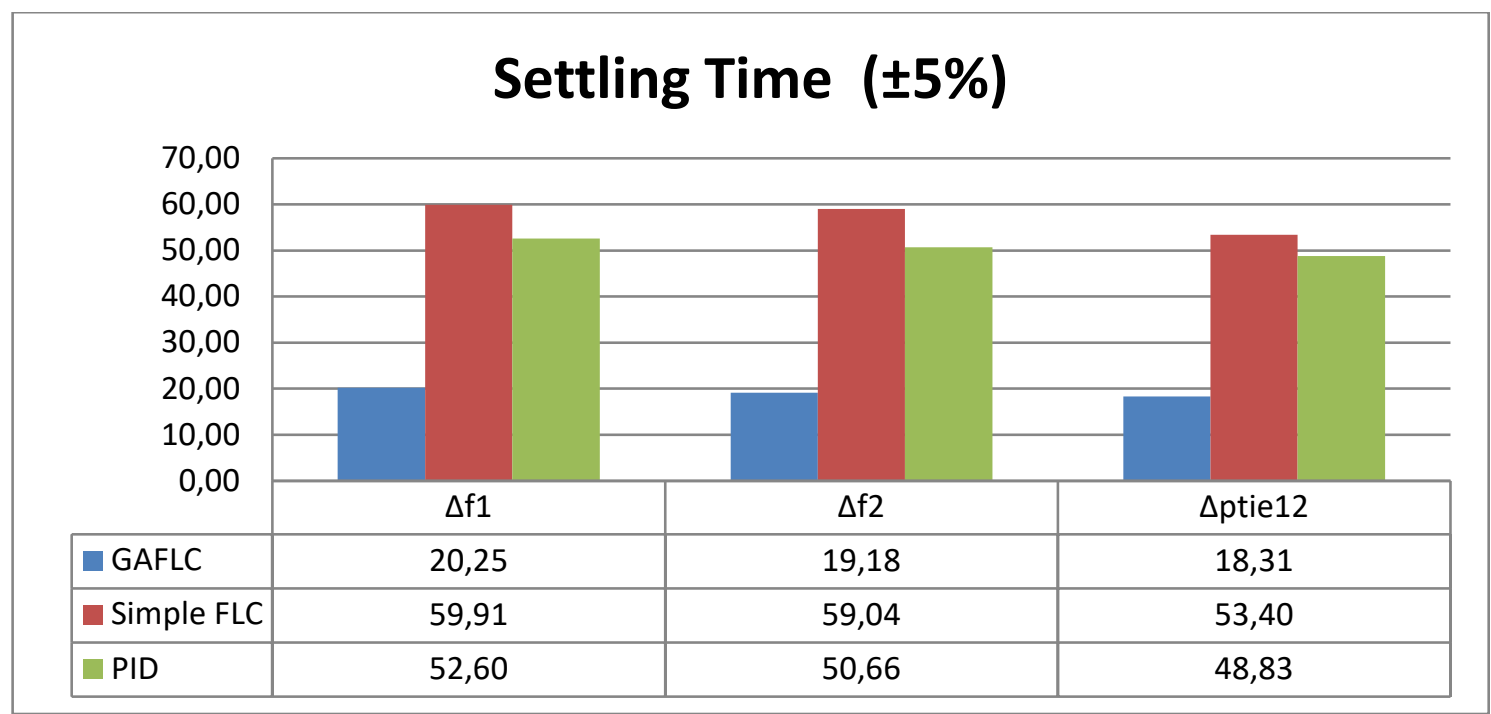

Figure 7 Settling Time comparison for different controllers

\section{B. Variable Load Demand from DISCOs}

The simulation was also repeated with instantaneous changes of load demand of various DISCOs at different time and simulation results show that proposed GA optimized FLC controller represents better dynamic performance in comparison to simple FLC and PID controller. The performance of proposed controller evaluated on basis of peak undershoot, settling time and two error function indexes (IAE and ITAE). Frequency deviation of area-1 and tie line deviation during variable load demand from DISCOs shown in Fig. 8. Performance indices captured at different time span are shown in Table 4 for different controllers. The simulation results show that GA optimized FLC for LFC in a deregulated environment results in substantial reduction in frequency and tie-line oscillations.

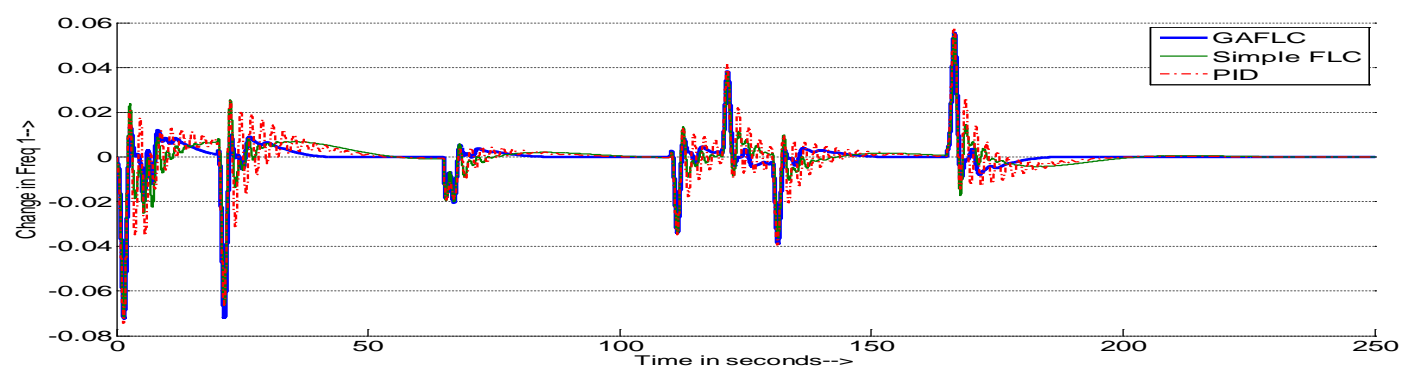

(a) 


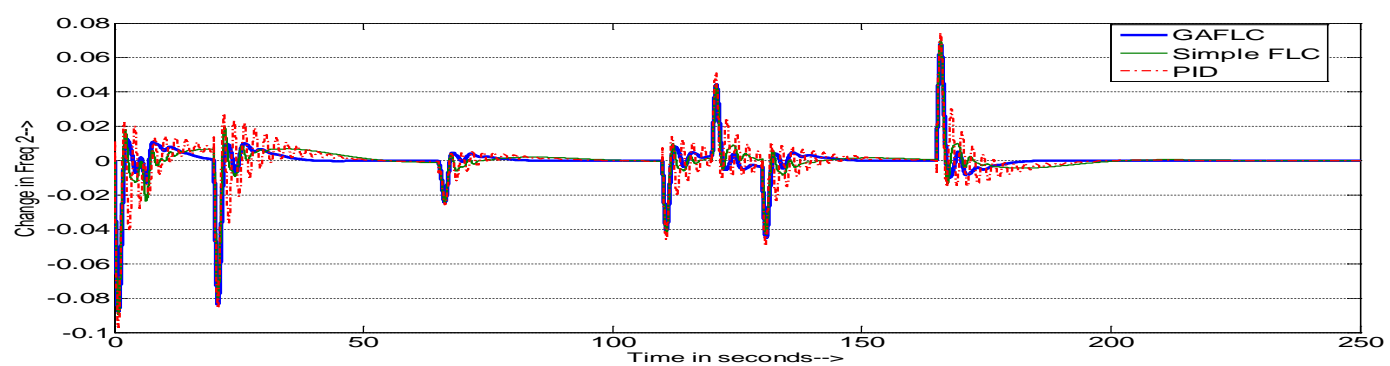

(b)

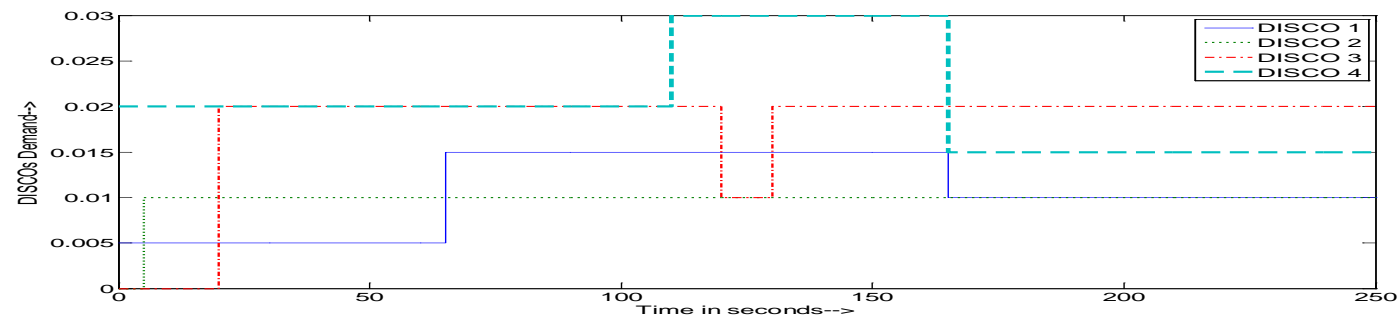

(c)

Figure 8 Comparison of GA optimized FLC, simple FLC and PID as per Test Case B (a) $\Delta f_{1}$, (b) $\Delta P_{t i e_{12}}$ and (c) demands of different DISCOs with respect to times

\section{Conclusion}

In this paper, GA optimized FLC is proposed for load frequency control of interconnected thermal-hydro power systems in a deregulated environment. The controller performance is compared on the basis of peak undershoot, peak overshoot and settling time. Results of simulation show that proposed controller provides a better performance compared to PID controller and simple FLC. The proposed controller's robustness also has been checked by varying load demand from different DISCOs, proving GA optimized FLC using two step optimization method provides a stable operation for an interconnected two area thermal-hydro power system in a deregulated environment.

\section{References}

[1] Donde Vaibhav, Pai M.A. and Hiskens Iran A. "Simulation and optimization in an AGC system after deregulation”, IEEE Trans Power System 2001; 16 (3): 481-8. 
[2] Nagrath I.J. and Kothari D.P. 1994. Power system engineering. Tata Mc-Graw Hill, New Delhi, India.

[3] Kundur, P. 1994. Power system stability and control”, McGraw-Hill, New York.

[4] Sathans, Swarup A., "Intelligent Load Frequency Control of Two-Area Interconnected Power System and Comparative Analysis” 2011 International Conference on Communication Systems and Network Technologies.

[5] Sreenath A., Atre Y.R.and Patil D.R., "Two Area Load Frequency Control with Fuzzy Gain Scheduling of PI Controller” First International Conference on Emerging Trends in Engineering and Technology, 2008.

[6] Çam E. and Kocaarslan I., "Load frequency control in two area power systems using fuzzy logic controller”, Energy Conversion and Management, Vol. 46, No. 2, 233-243, 2005.

[7] Mathur H.D., Manjunath H.V., "Frequency stabilization using fuzzy logic based controller for multiarea power system”, The South Pacific Journal of Natural Science, 2007, 4, 22-30.

[8] Chown GA. and Hartman R.C., "Design and Experience with a Fuzzy Logic Controller for Automatic Generation Control (AGC)”, IEEE Transactions on Power Systems, Vol. 13, No. 3, August 1998, 965-970.

[9] Hemmati R., Boroujeni S. M. S., Delafkar H. and Boroujeni A. S., "Fuzzy load frequency control in multi area electric power system”, Indian Journal of Science and Technology, Vol. 4 No. 7 (July 2011), 796-800.

[10] Parashuramulu B.and Kumar Ashwani, "Load Frequency Control of Hybrid Systems in Open Access Environment”, 2010 Annual IEEE India Conference (INDICON), 0-3, 2010.

[11] Paridal M. and Nandal J., "Automatic Generation Control of a Hydro-Thermal System in Deregulated Environment”, Electrical Machines and Systems, 2005. ICEMS 2005, Vol. 2, 942 - 947, 2005

[12] Jerry J. Ancona: “A bid solicitation and selection method for: developing a competitive spot priced electric market”, IEEE Trans. on Power systems, vol.12, no.2, May, 1997.

[13] Fosha C.E. and Elgead O.I., “The megawatt frequency control problem: A new approach via optimal control theory”, IEEE Trans. on Power Systems, Vol. PAS-89.563-577, 1970.

[14] Bhatt, P., Roy, R. \& Ghoshal, S.P., “Optimized multi area AGC simulation in restructured power systems”, International Journal of Electrical Power \& Energy Systems, 32(4), pp.311-322, 2010

[15] Gozde H. and Taplamacioglu M. C., “Automatic generation control application with craziness based particle swarm optimization in a thermal power system”, Electrical Power and Energy Systems, Vol. 33, issue. 1, January 2011, pp. 8-16.

[16] Tripathy, S.C., Hope, G.S. \& Malik, O.P., Optimisation of load-frequency control parameters for power systems with reheat steam turbines and governor deadband nonlinearity. In IEE PROC. pp. 10-16, 1982 
[17] Ziegler J.G.and Nichols N.B., “Optimum settings for automatic controllers”, Trans. ASME, 65(5), pp. 433-444, 1942.

[18] MathWorks - MATLAB and Simulink for Technical Computing www.mathworks.com.

[19] Boesack, C.D., Marwala, T. \& Nelwamondo, F. V., 2010. Application of GA-Fuzzy Controller design to Automatic Generation Control. Third International Workshop on Advanced Computational Intelligence, pp.227-232.

[20] LEE, C.C., 1990. Fuzzy Logic in Control Systems : Fuzzy Logic Controller-Part I. IEEE transactions on systems, man, and cybernetics. Part B, Cybernetics : a publication of the IEEE Systems, Man, and Cybernetics Society, 20(2), pp.404-418.

[21] RenHou Li and Zhang Yi, "Fuzzy logic controller based on genetic algorithms”, Fuzzy Sets and Systems 83 (1996) 1-10.

[22] Goldberg D.E., Genetic Algorithms in Search, Optimization, and Machine Learning. Reading, MA: Addison-Wesley 1989.

[23] Panda, S., \& Yegireddy, N. K. (2013). Automatic generation control of multi-area power system using multi-objective non-dominated sorting genetic algorithm-II. International Journal of Electrical Power \& Energy Systems, 53, 54-63.

\section{Appendix}

Table 4

Performance Indices of different controllers for variable load test case

\begin{tabular}{|c|c|c|c|c|c|c|c|}
\hline \multirow{2}{*}{$\begin{array}{l}\text { Error } \\
\text { Index }\end{array}$} & \multirow{2}{*}{$\begin{array}{c}\text { Controller } \\
\text { Type }\end{array}$} & \multicolumn{6}{|c|}{ Simulation Time (T), in Sec } \\
\hline & & $T=0$ & 50 & 100 & 150 & 200 & 250 \\
\hline Peak & GAFLC & 0 & 0.013439 & 0.013439 & 0.038170 & 0.055520 & 0.055520 \\
\hline Overshoot & Simple FLC & 0 & 0.025543 & 0.025543 & 0.037581 & 0.055317 & 0.055317 \\
\hline$\Delta f_{1}$ & PID & 0 & 0.025036 & 0.025036 & 0.041313 & 0.057586 & 0.057586 \\
\hline Peak & GAFLC & 0 & 0.012701 & 0.012701 & 0.044251 & 0.067756 & 0.067756 \\
\hline Overshoot & Simple FLC & 0 & 0.019346 & 0.019346 & 0.044330 & 0.069597 & 0.069597 \\
\hline$\Delta f_{2}$ & PID & 0 & 0.027552 & 0.027552 & 0.051470 & 0.074535 & 0.074535 \\
\hline Peak & GAFLC & 0 & 0.021667 & 0.021667 & 0.021667 & 0.021647 & 0.021647 \\
\hline Overshoot & Simple FLC & 0 & 0.020793 & 0.020793 & 0.020793 & 0.020793 & 0.020793 \\
\hline$\Delta$ ptie $_{12}$ & $P I D$ & 0 & 0.020517 & 0.020517 & 0.020517 & 0.020517 & 0.020517 \\
\hline Peak & GAFLC & 0 & 0.072289 & 0.072289 & 0.072289 & 0.072225 & 0.072225 \\
\hline Undershoot & Simple FLC & 0 & 0.071600 & 0.071600 & 0.071600 & 0.071600 & 0.071600 \\
\hline$\Delta f_{1}$ & PID & 0 & 0.074511 & 0.074511 & 0.074511 & 0.074511 & 0.074511 \\
\hline Peak & GAFLC & 0 & 0.087791 & 0.087791 & 0.087791 & 0.087569 & 0.087569 \\
\hline Undershoot & Simple FLC & 0 & 0.089707 & 0.089707 & 0.089707 & 0.089707 & 0.089707 \\
\hline$\Delta f_{2}$ & PID & 0 & 0.096909 & 0.096909 & 0.096909 & 0.096909 & 0.096909 \\
\hline Peak & GAFLC & 0 & 0.008750 & 0.008750 & 0.011589 & 0.015775 & 0.015775 \\
\hline Undershoot & Simple FLC & 0 & 0.009845 & 0.009845 & 0.011298 & 0.016237 & 0.016237 \\
\hline$\Delta p t i e_{12}$ & PID & 0 & 0.008908 & 0.008908 & 0.012582 & 0.015744 & 0.015744 \\
\hline Settling & GAFLC & 0 & 39.56 & 81.61 & 148.28 & 183.45 & 183.45 \\
\hline Time & Simple FLC & 0 & $>50$ & 99.66 & $>150$ & $>200$ & 217.27 \\
\hline$\Delta f_{1}$ & PID & 0 & $>50$ & 96.15 & $>150$ & 197.59 & 197.59 \\
\hline Settling & GAFLC & 0 & 38.52 & 80.72 & 147.33 & 182.59 & 182.59 \\
\hline Time & Simple FLC & 0 & $>50$ & 98.79 & $>150$ & 199.63 & 216.34 \\
\hline$\Delta f_{2}$ & PID & 0 & $>50$ & 95.38 & $>150$ & 196.87 & 196.87 \\
\hline Settling & GAFLC & 0 & 37.71 & 78.17 & 146.21 & 180.41 & 180.41 \\
\hline Time & Simple FLC & 0 & $>50$ & 94.65 & $>150$ & 197.19 & 197.19 \\
\hline$\Delta p t i e_{12}$ & PID & 0 & 48.28 & 91.41 & 149.95 & 193.18 & 193.18 \\
\hline IAE & GAFLC & 0 & 306.25 & 361.71 & 555.15 & 669.10 & 669.50 \\
\hline
\end{tabular}




\begin{tabular}{cccccccc} 
& Simple FLC & 0 & 389.82 & 480.92 & 687.94 & 863.02 & 874.30 \\
& PID & 0 & 490.68 & 587.13 & 890.82 & 1102.95 & 1113.54 \\
\hline \multirow{3}{*}{ ITAE } & GAFLC & 0 & 4435.57 & 8309.66 & 32367.60 & 51767.44 & 51850.14 \\
& Simple FLC & 0 & 7051.52 & 13714.09 & 39419.33 & 69679.72 & 72117.79 \\
& PID & 0 & 8466.22 & 15429.56 & 53353.37 & 89774.09 & 92030.67 \\
\hline
\end{tabular}

